\title{
New Resist and Underlayer Approaches toward EUV Lithography
}

\author{
Juha Rantala*a, Thomas Gädda*a, Markus Laukkanen ${ }^{\text {a }}$, Nguyen Dang Luong*a , Kimmo Karaste ${ }^{\text {a }}$, \\ Dimitrios Kazazis ${ }^{\mathrm{b}}$, and Yasin Ekinci ${ }^{\mathrm{b}}$ \\ a PiBond Oy, Kutojantie 2, 02630 Espoo, Finland \\ ${ }^{\mathrm{b}}$ Paul Scherrer Institute, 5232 Villigen PSI, Switzerland
}

\begin{abstract}
Extreme ultraviolet lithography (EUVL, $\lambda=13.5 \mathrm{~nm}$ ) is the most promising candidate to pattern the finest features in the next-generation integrated circuit manufacturing. Chemically-amplified resists (CARs) have long been used as state-ofthe art photoresists and have been considered as EUV resist. Recently, inorganic and metal-containing resist materials have received significant attention in both academia and industry areas, with the aim to improve the resist performance in terms of resist resolution (R), line-edge roughness (LER), and sensitivity (S) to solve the well-known RLS trade-off. However, the resists reported to date usually have either problem in terms of RLS trade-off or pose metal contamination, which is a serious issue in expensive EUV equipment. Differently, in this report, we demonstrate our recent success in the development of the photochemistry of silicon compounds and resist formulations to obtain novel EUV negative tone resists with high resolution (up to $22 \mathrm{~nm}$ pitch line/space patterns), low line-edge roughness (1-3nm) with reasonable EUV sensitivity. We also discuss their high etch selectivity to a PiBond's SOC organic underlayer, which enable a bilayer lithography stack for EUVL patterning. Their excellent etch performances by RIE plasma is also reported.
\end{abstract}

Keywords: structure-property correlation, silicon compounds, EUV lithography, E-beam lithography, RLS trade-off, Non-CAR

\section{INTRODUCTION}

The semiconductor industry has followed Moore's law stating the observation that the number of transistors in a dense integrated circuit doubles approximately every two years. This is achieved by the printing of ever smaller features on semiconductor substrates. The achievement has been permitted by improved materials and shortening of the wavelength of the emitted light. This trend is continuing with the aim of achieving sub-20nm half-pitch (HP) resolution mass production by the deployment of EUVL with a $13.5 \mathrm{~nm}$ wavelength of emitted light. ${ }^{1-3}$

EUVL requires high-performance photoresists with high sensitivity $\left(<50 \mathrm{~mJ} / \mathrm{cm}^{2}\right)$ for the reduction of the cost of development of high-power exposure sources and operating cost/throughput. Chemically amplified resists (CAR), the current material that has been in use for decades, may exhibit a good sensitivity (S) but its drawbacks are resolution (R) and line-width-roughness (LWR). ${ }^{3}$ Thus, the industry is facing a challenge where these three parameters are not simultaneously satisfied resulting in an RLS trade-off which must be solved. ${ }^{4}$

Traditional CARs are mainly composed of organic materials with low EUV absorption and functional chemical components such as photoacid generators (PAG) and quenchers. The CARs have several disadvantages, particularly when aiming for sub-20nm features, such as the need for higher dose, pattern collapse, limited etch selectivity, and consequent need for multilayer stacks.

Secondary electrons are responsible for PAG decomposition but due to the electron blur and acid diffusion, the chemical reaction can take place a few nanometers away from the EUV absorption site. The decreased electron blur results in increased need in the number of acids to be created, leading to increased EUV dose requirement. Having low LWR while

International Conference on Extreme Ultraviolet Lithography 2018, edited by Kurt G. Ronse,

Eric Hendrickx, Patrick P. Naulleau, Paolo A. Gargini, Toshiro Itani, Proc. of SPIE Vol. 10809,

108090X · @ $2018 \mathrm{SPIE} \cdot$ CCC code: 0277-786X/18/\$18 · doi: 10.1117/12.2503107 
using high sensitivity resist (high sensitivity=low dose) is another challenge for EUV resists, due to photon shot noise effects. The resolution of CAR may also be affected by pattern collapse, which becomes increasingly important as feature sizes move into the sub-20 nm size range. The challenges with CARs indicate the limitations are intimately tied to the nature of the chemical amplification imaging mechanism, the thin-film confinement effects and the polymer molecular properties.

Recently, molecular metal-containing resists have been employed with benefits over CARs. A key driver has been to draw from the benefits of higher atomic absorption coefficients compared to CARs which are based on carbon. Particularly certain semimetals such as Sn display high elemental absorption cross-sections at EUV wavelength. Several studies on CARs which have been additivized by the addition of such metals have been reported. In past years, resists based on metaloxo clusters, nanoparticles and molecular resists have been used with improved results. ${ }^{5}$ Metal-containing resists have several benefits including stack simplification due to simultaneous imaging and suitable etch pattern transfer properties, and improved sensitivity for EUV resulting in partial solutions for RLS tradeoff. However, their main disadvantage is that metals are strongly disfavored in the fabrication of integrated circuits as they can disrupt the function of transistors, and that LER characteristics require improvement. Furthermore, it has been noted that in EUV scanner, the metal species in metal-containing resists interact with atomic $\mathrm{H}$ or radical $\mathrm{H}^{*}$ form metallic hydrides $\left(\mathrm{M}_{\mathrm{x}} \mathrm{H}_{\mathrm{y}}\right)$ which may be a risk item to optics lifetime. In addition, high LER is a problem in both metal-based and chemically amplified resists. ${ }^{3}$

Another type of resist is hydrogensilsesquioxane (HSQ). HSQ is a widely utilized negative-type electron-beam resist material. EUV patterning down to $7 \mathrm{~nm}$ HP is demonstrated with this resist. ${ }^{6}$ Due to its potential for high density patterns, namely, less than $20 \mathrm{~nm}$ pitch structures, intensive investigations have been carried out to find an optimum process. However, it suffers from very low sensitivity $\left(>600 \mathrm{~mJ} / \mathrm{cm}^{2}\right)$, requires concentrated developers and is known to be relatively unstable during processing rendering its industrial adoption limited as described previously. ${ }^{6,7}$

Herein we report novel resist materials and formulations based on silicon chemistry yielding EUV resists with excellent characteristics. The materials exhibit low LER, good sensitivity, excellent etch resistance, and good post coating delay.

\section{Material design strategy}

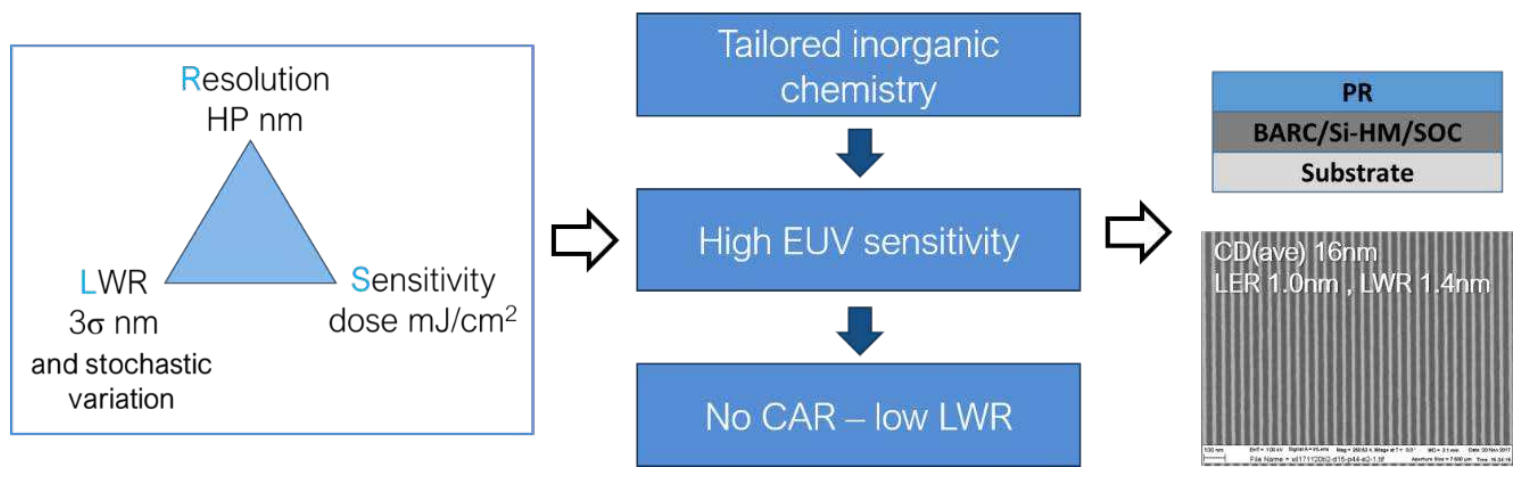

Figure 1. Resist challenge in EUVL and strategies to solve issues.

\section{METHODOLOGY}

\subsection{Materials}

The materials discussed in this manuscript have been described in Table 1. All materials were prepared by controlled hydrolysis of organosilane precursors in suitable solvents. The obtained materials were then formulated in PGMEA. The formulations were filtered through a $0.2 \mu \mathrm{m}$ PTFE filter prior to use. 
Table 1. GPC data and post coating delay of two EUV negative tone resists and one SOC underlayer material.

\begin{tabular}{|c|c|c|c|c|c|}
\hline $\begin{array}{c}\text { PiBond's EUV resists + SOC } \\
\text { underlayer package }\end{array}$ & Type & $\begin{array}{c}\text { Molecular } \\
\text { weight by GPC } \\
{[\mathbf{g} / \mathbf{m o l}]}\end{array}$ & $\begin{array}{c}\text { Film thickness* } \\
{[\mathbf{n m}]}\end{array}$ & \multicolumn{2}{|c|}{$\begin{array}{c}\text { Post coating delay** } \\
\mathbf{8 0}\end{array}$} \\
\hline PRE 104A negative tone resist & Organohydrogensilsesquioxane & 3000 & $40 \pm 2$ & $\mathrm{X}$ & $\mathrm{X}$ \\
\hline PRE 104B negative tone resist & Organohydrogensilsesquioxane & 5000 & $40 \pm 2$ & $\mathrm{X}$ & $\mathrm{X}$ \\
\hline SOC 400 organic underlayer & Spin on carbon & 3200 & $40 \pm 2$ & NA $^{* * *}$ & NA*** \\
\hline
\end{tabular}

* After soft bake at $80^{\circ} \mathrm{C} / 1 \mathrm{~min}$

** X: good for at least $24 \mathrm{~h}$ of PCD after bake at $80^{\circ} \mathrm{C}$ and $120^{\circ} \mathrm{C}$.

$* * *$ NA: PCD is not applied for SOC underlayer.

\subsection{Material characterizations}

Gel permeation chromatography data was collected on an Agilent 1260 Infinity LC equipped with Shodex KF columns (KF-G; KF-803L; KF-802; KF-801) connected in series. The detector and column temperature were held at $40{ }^{\circ} \mathrm{C}$. Flow rate of THF eluent was $1.0 \mathrm{ml} / \mathrm{min}$.

Ageing study was performed on samples with storage conditions of $-18{ }^{\circ} \mathrm{C}, 4{ }^{\circ} \mathrm{C}$ and $23{ }^{\circ} \mathrm{C}$ conditions. GPC was used to monitor the molecular weight.

Trace metal was measured with an Agilent ICP-MS (Perkin Elmer Elan DRC II + Perkin Elmer AS 93Plus Autosampler).

\subsection{Film Characterization and Patterning}

Post coating delay (PCD) was carried out to evaluate long erm stability of the coatings prior to exposure and development. The result is summarized in Table 2 . In this test, the $2 \%$ solutions were spin coated on silicon wafer at $1500 \mathrm{rpm}$ for $20 \mathrm{~s}$. Soft bake was then carried out on a hot plate with temperature ranging from $80{ }^{\circ} \mathrm{C}$ to $150{ }^{\circ} \mathrm{C}$ for 1 minutes. The film thicknesses were determined via Woollam ellipsometer (M2000D) to be $40 \pm 2 \mathrm{~nm}$. The films were stored at room temperature for $1 \mathrm{~h}$ and $24 \mathrm{~h}$ under ambient conditions, and then developed with $2.38 \% \mathrm{TMAH}$, rinsed with deionized water and dried with nitrogen gas. The film thicknesses before and after development were measured to evaluate PCD. PCD was considered to be good if the film was totally removed by TMAH developer after soft bake and the two delay times. The result is summarized in Table 1.

EUV lithography was carried out using a XIL-II EUV tool at Paul Scherrer Institute, Villigen, Switzerland. Process steps use in the in EUV lithography evaluation is summarized in Table 2.

E-beam lithography was carried out on a Vistec EPBG5000pES tool. The e-beam doses were varied from 100 to 1200 $\mu \mathrm{C} / \mathrm{cm}^{2}$ at $100 \mathrm{kV}$ and current of $0.5-1 \mathrm{nA}$. The development steps were carried out similarly as described above for the EUV lithography.

For patterning of PRE 104B resist on SOC substrate: PiBond SOC 400 was spin coated on silicon wafer at $1500 \mathrm{rpm}$ for 20 seconds. Curing of SOC film was carried out at $150{ }^{\circ} \mathrm{C}$ for $1 \mathrm{~min}$ and $400{ }^{\circ} \mathrm{C}$ for 2 minutes. The resist was then coated on SOC with the same condition as described above.

Scanning electron micrographs were obtained via Zeiss Supra VP55 high resolution field emission scanning electron microscope. Sample coating was not used for all measurements.

The etch tests were carried out with $\mathrm{O}_{2}$ and $\mathrm{CF}_{4}$ gases with the RIE recipe in Figure 8 using an Oxford Plasmalab 80. The film was etched for time intervals of 60 seconds for 300 seconds. 
Table 2. Summarize steps in EUV lithography.

\begin{tabular}{|c|c|c|}
\hline Process step & Parameters & Other information \\
\hline Spin coat & $1500 \mathrm{rpm}, 20 \mathrm{~s}$ & $2 \mathrm{ml}$ dispense volume for 4-inch wafer \\
\hline Pre Bake (Soft Bake) & $80^{\circ} \mathrm{C}-120^{\circ} \mathrm{C}, 60 \mathrm{~s}$ & Hot plate, contact \\
\hline EUV exposure & $2-150 \mathrm{~mJ} / \mathrm{cm}^{2}$ & Dose to size at PSI \\
\hline Post exposure bake & Optionally use & Optionally use \\
\hline Development & $\mathrm{TMAH} 2.38 \%, 1-2 \mathrm{~min}$ & Immersion development. \\
\hline Rinse & DIW, $10 \mathrm{~s} \times 3$ times & Manual spray \\
\hline Dry & $\mathrm{N}_{2} /$ compressed air & Manual \\
\hline
\end{tabular}

\section{RESULTS AND DISCUSSION}

\subsection{EUV lithography}

A resist must have a sufficiently good post coating stability to be applicable for industrial use, i.e. that the coating performs in a similar manner immediately after coating and several hours after coating and soft bake. The two EUV resists prepared for patterning test were subjected to a $1 \mathrm{~h}$ and $24 \mathrm{~h}$ long PCD test. As seen resists A, and B show good PCD in test, suggesting that the long-term stability of coatings is good. In addition, we evaluated the stability of the resist solutions for long term storage properties. The aging study on the resist was carried out at three different temperatures which are $-18{ }^{\circ} \mathrm{C}, 4{ }^{\circ} \mathrm{C}$, and $23{ }^{\circ} \mathrm{C}$. The resists have been found to be stable at $-18{ }^{\circ} \mathrm{C}$ and $4{ }^{\circ} \mathrm{C}$ for at least two months and at $23{ }^{\circ} \mathrm{C}$ for at least 7 days.

As discussed above, an industrially applicable EUV resist must also exhibit sufficient sensitivity, resolution and line width roughness. EUV lithographic imaging using EUV lithography of PRE 104A and PRE 104B is presented in Figure 2. LER was analyzed via SuMMIT Litho Analysis and Nanometrisis (NanoLER) softwares. We show here that both PRE 104A and PRE 104B could be used for patterning HP of $22 \mathrm{~nm}$ with a low LER of $1 \mathrm{~nm}$ and $3.3 \mathrm{~nm}$, respectively. The plot on the right shows the power spectrum density (PSD) of left and right edges of PRE 104A measured for $22 \mathrm{~nm}$ HP pattern. It is clearly demonstrating that right and left edges are very similar. In comparison, the PRE 104A possesses much lower LER compared with that of PRE 104B, however it has lower sensitivity. 


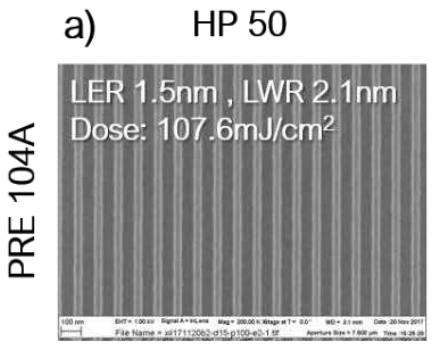

e)

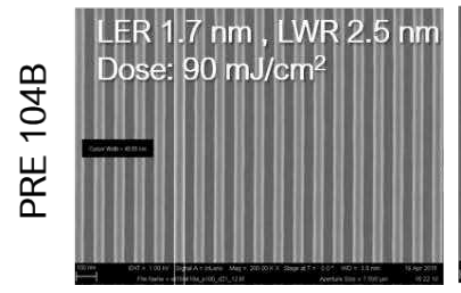

b) $\quad$ HP 30

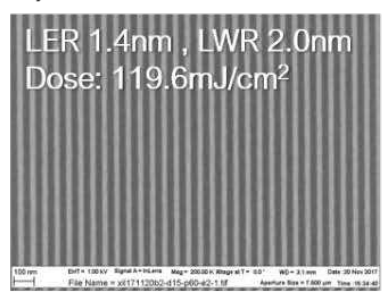

f)

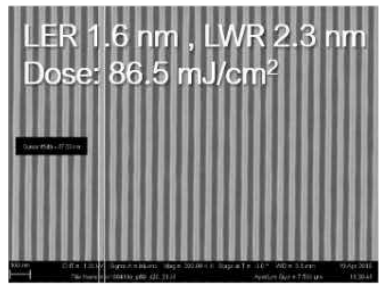

c) HP 22

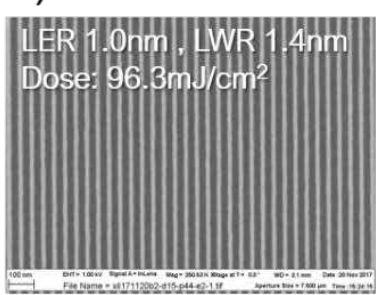

g)

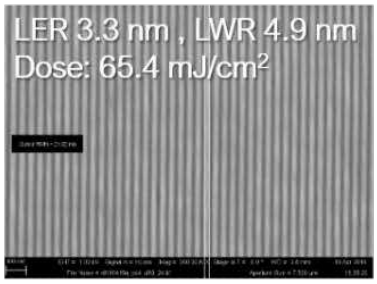

d)

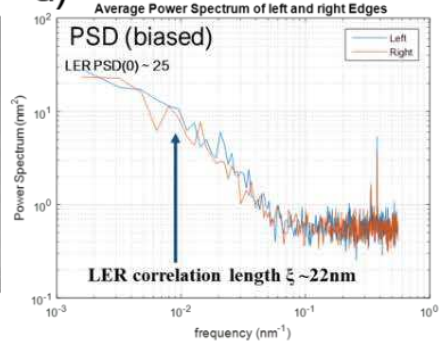

Figure 2. EUV performance of PRE104A (a-d), PSD curves of 22-nm HP pattern for right and left edges (d), and PRE104B (e-g). EUV performance of these negative tone resists was studied at different resolution and doses. Doses in the images are the optimized values for $\mathrm{HP}$ of $22 \mathrm{~nm}, 30 \mathrm{~nm}$, and $50 \mathrm{~nm}$.

\subsection{Bake temperature and underlayer effects to EUVL}

We carried out a study on the effect of two different baking temperatures of $80^{\circ} \mathrm{C}$ and $120^{\circ} \mathrm{C}$ on patterning performance of PRE 104B as shown in Figure 3. The higher baking temperature showed improved sensitivity which is approximately $34 \%$ less in dose.

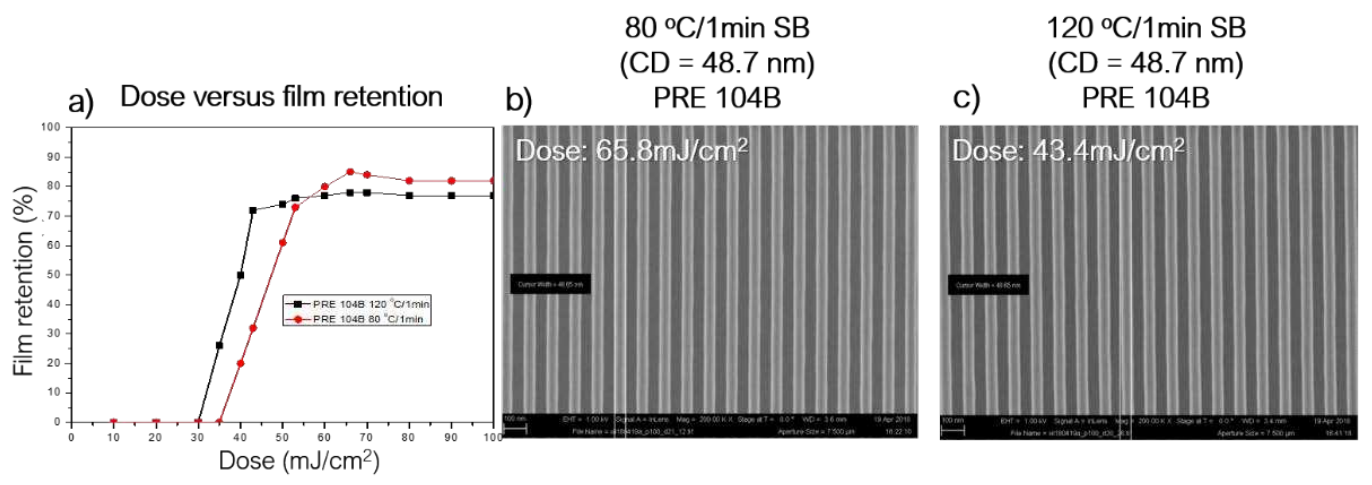

Figure 3. Effect of soft bake temperatures $80{ }^{\circ} \mathrm{C} / 1 \mathrm{~min}$ and $120^{\circ} \mathrm{C} / 1 \mathrm{~min}$ on a) film retention b) $50 \mathrm{~nm}$ pattern using $80{ }^{\circ} \mathrm{C}$ and c) 50 nm pattern using $120^{\circ} \mathrm{C}$ bake.

In additional to EUVL, e-beam has also been used to print features on the resists A-C. E-beam has been similarly used to examine the effect of baking conditions, and patterning performance on silicon and SOC underlayers. The effect of baking conditions on the patterning is presented in Figure 4using $50 \mathrm{~nm}$ lines with $\mathrm{L} / \mathrm{S}$ ratio of $1 / 1$ as an example. While figure 3 shows the effect of soft bake, we found that the use of a post exposure bake $\left(80^{\circ} \mathrm{C}, 1 \mathrm{~min}\right)$ decreased the dose with $29 \%$. In another experiment we used soft bake condition of $120^{\circ} \mathrm{C} / 1 \mathrm{~min}$ and the required dose was smaller by $33 \%$ compared to the sample with soft bake of $80{ }^{\circ} \mathrm{C} / 1 \mathrm{~min}$. Thus, increase of soft bake temperatures or the use of a post exposure bake 
step decrease the done needed for patterning. However, the effect of increased soft bake was more significant suggesting that the patterning process can well be carried out without the use of a PEB step.

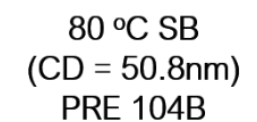

PRE 104B

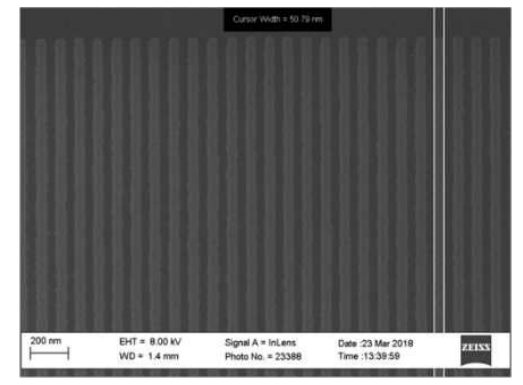
$80^{\circ} \mathrm{C} \mathrm{SB}+80^{\circ} \mathrm{C} \mathrm{PEB}$
$(\mathrm{CD}=51.9 \mathrm{~nm})$
PRE 104B

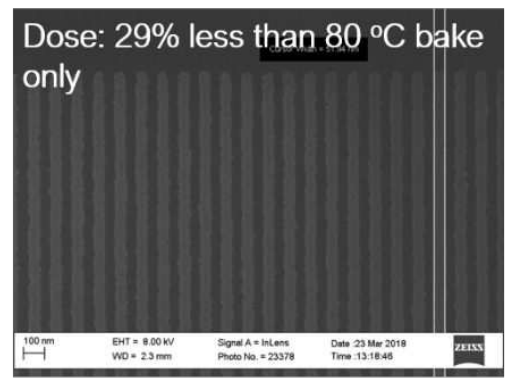

Figure 4. E-beam result of PRE 104B with and without PEB. A pattern of 50-nm lines was used for the study.

Next, we compared the performance of the PRE 104B resist on silicon and spin on carbon (SOC) substrates using e-beam patterning. A 50-nm line pattern was used in both cases. The result in Figure 5 shows that the lines are of similar quality on both substrates, however with around $20 \%$ more dose on SOC substrate than in Si substrate. This phenomenon will be further studied with EUVL.
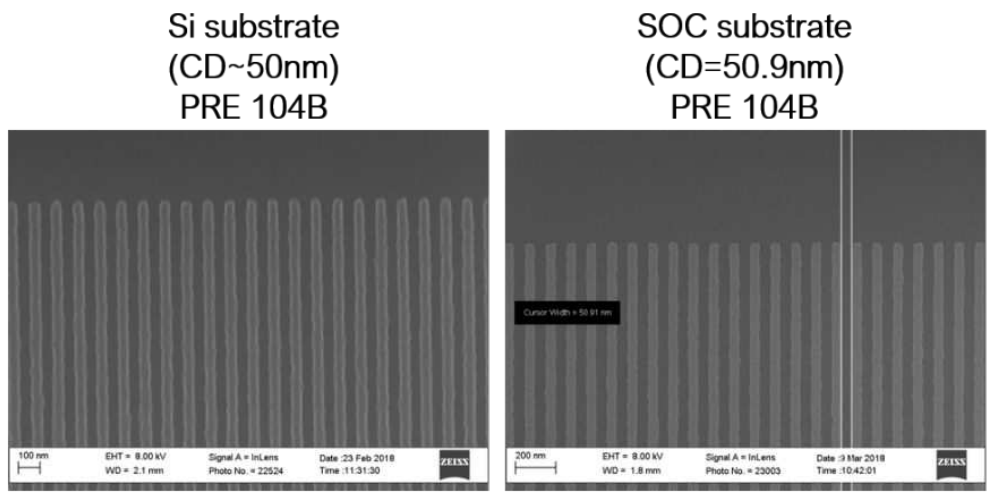

Figure 5. E-beam performance of PRE 104B on Si and SOC substrates showing around 20\% more dose on SOC substrate than in Si substrate.

\subsection{EUV lithography versus e-beam lithography}

We compared the result of PRE 104B performance via EUV and e-beam patterning (Figure 6). Both patterning techniques show similar trend with and increased dose required to reach the match the targeted pattern or mask size. Furthermore, the results indicate that EUV shows better patterning performance compared with e-beam due to the significantly lower LWR. Nevertheless, the e-beam tool factor may also play an important role as the tool has a $10 \mathrm{~nm}$ beam size and $5 \mathrm{~nm}$ 'movement' and thus may be a key contributor to the rougher line edges for e-beam patterning. 

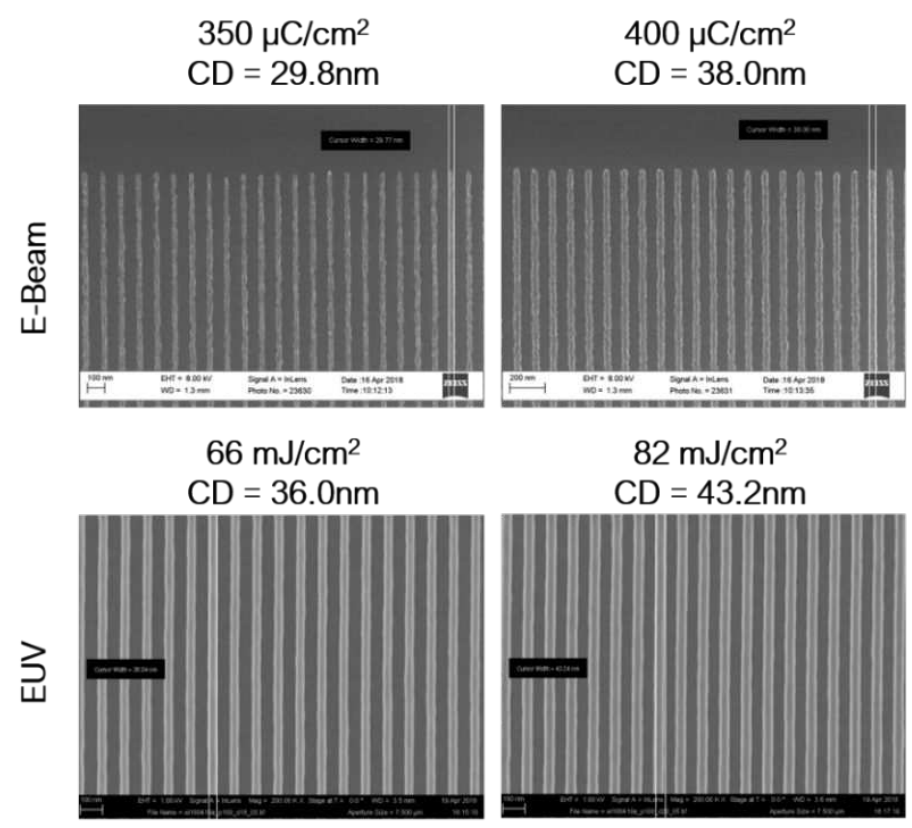

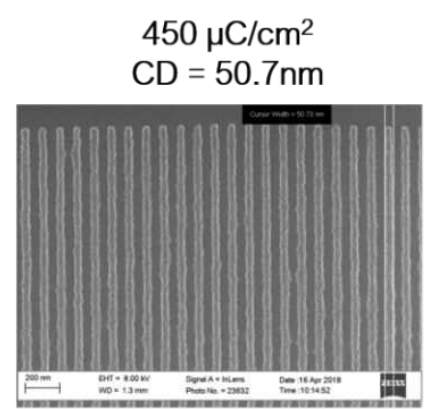

$90 \mathrm{~mJ} / \mathrm{cm}^{2}$

$\mathrm{CD}=48.7 \mathrm{~nm}$

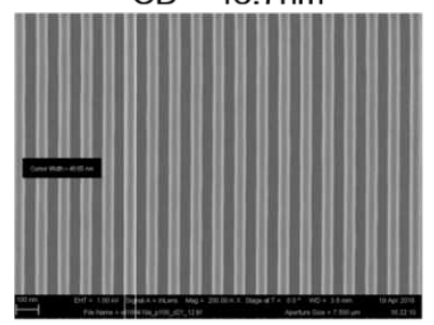

Figure 6. Performances of PRE 104B resist in EUV and E-beam lithography.

\subsection{Etch resistance and etch selectivity with SOC organic underlayer}

One of the most important characteristics of EUV photoresist is its etch resistance. Etch rates and selectivities determination of the film thicknesses before and after etches using Spectroscopic Ellipsometry (Figure 7). The etch rate using fluorine etch chemistry shows a relatively stable etch rate of $\sim 62 \mathrm{~nm} / \mathrm{min}$ for the resist B with all bake temperatures tested. The $\mathrm{O}_{2}$ etch rate, on the other hand, shows a decreasing trend. The etch rate after an $80{ }^{\circ} \mathrm{C} / 1 \mathrm{~min}$ bake is $\sim 7 \mathrm{~nm} / \mathrm{min}$ and appears to plateau already after $120^{\circ} \mathrm{C} / 1 \mathrm{~min}$ bake temperature to $4-5 \mathrm{~nm} / \mathrm{min}$. The $\mathrm{SOC}$ etch rates were measured to be $336 \mathrm{~nm} / \mathrm{min}$ and $31 \mathrm{~nm} / \mathrm{min}$ in $\mathrm{O}_{2}$ and $\mathrm{CF}_{4}$ plasma, respectively. The etch selectivity to SOC thus improves from 1:45 to 1:70 with the increase in bake temperature. The excellent etch selectivity suggests that the material can be used to enable a bilayer resist stack and that the etch selectivity permits thinning of the coatings, and consequently offers a route to further resolution improvement. 


\section{a)}

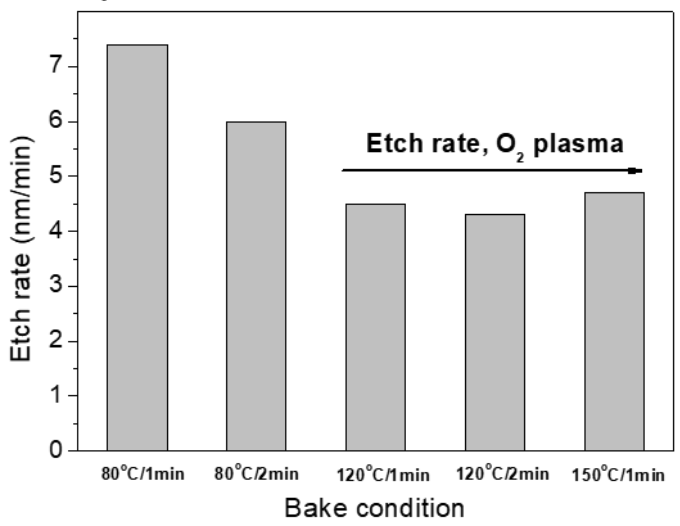

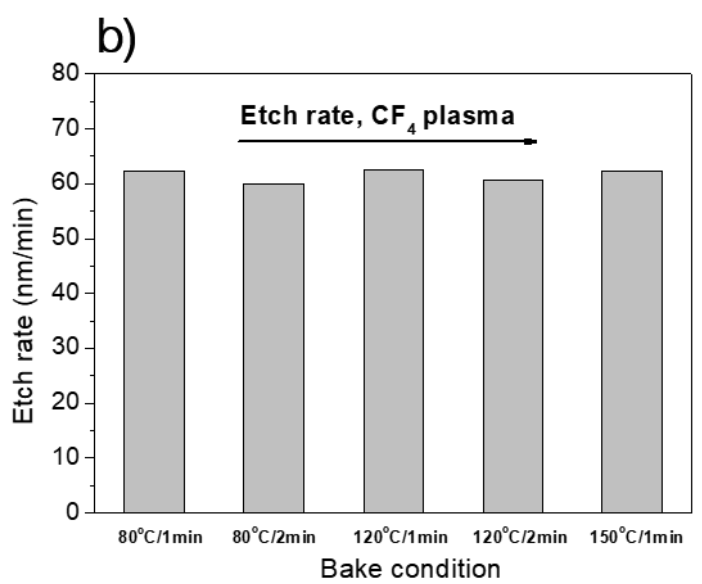

Figure 7. Etch performances of the PRE 104B in $\mathrm{O}_{2}$ plasma (a) and $\mathrm{CF}_{4}$ plasma (b). Powers of $250 \mathrm{~W}$ at pressure of 50 mTorr and $200 \mathrm{~W}$ at pressure of $30 \mathrm{mTorr}$, for $\mathrm{O}_{2}$ and $\mathrm{CF}_{4}$, respectively.

\section{SUMMARY AND CONCLUSIONS}

Herein we have reported novel EUV resists based on organohydrogen silsesquioxane chemistry. The materials function as negative tone resists due to the crosslinking reactions that cause the solubility switch of the materials rendering the exposed areas insoluble to the developer. The materials described exhibit low LWR $(<2 \mathrm{~nm})$, sufficient sensitivity $\left(40-60 \mathrm{~mJ} / \mathrm{cm}^{2}\right)$, excellent etch selectivity and ability to form pattern by industry standard aq. TMAH development processes after exposure. The etch performance and the bake temperature studies suggest that the materials can be used to simplify both the lithographic stack and the patterning process due to bilayer structure and no need for a PEB step, respectively.

\section{ACKNOWLEDGMENTS}

This project has received partial funding from the EU-H2020 research and innovation programme under grant agreement No 654360 having benefitted from the access provided by the Paul Scherrer Institut in Villigen within the framework of the NFFA-Europe Transnational Access Activity.

\section{REFERENCES}

[1] Bakshi V., EUV lithography, Bellingham, Washington, USA: SPIE Press, (2018).

[2] Mojarad, N., Gobrecht, J. and Ekinci, Y., "Beyond EUV lithography: a comparative study of efficient photoresists' performance," Sci. Rep. 5, 9235 (2015).

[3] De Simone, D., Vesters, Y. and Vandenberghe, G., "Photoresists in extreme ultraviolet lithography (EUVL)," Adv. Opt. Technol. 6, 163-172 (2017).

[4] Higgins, C. D., Szmanda C. R., Antohe, A., Denbeaux, G., Georger, J. and Brainard R. L. "Resolution, line-edge roughness, sensitivity tradeoff, and quantum yield of high photo acid generator resists for extreme ultraviolet lithography,” Jpn. J. Appl. Phys. 50, 1-8 (2011).

[5] Jiang, J., Zhang, B., Yu, M., Li, L., Neisser, M., Chun, J.S., Giannelis, E.P. and Ober, C.K., "Oxide Nanoparticle EUV (ONE) Photoresists: Current Understanding of the Unusual Patterning Mechanism," J. Photopolym. Sci. Technol., 28(4), 515-518 (2015).

[6] Single-digit-resolution nanopatterning with extreme ultraviolet light for the $2.5 \mathrm{~nm}$ technology node and beyond $\mathrm{N}$. Mojarad, M. Hojeij, L. Wang, J. Gobrecht, and Y. Ekinci, Nanoscale 7, 4031 (2015).

[7] Yang, J. K. W., Cord, B., Duan, H. and Berggren. "Understanding of hydrogen silsesquioxane electron resist for sub-5-nm-half-pitch lithography,” J. Vac. Sci. Technol. B Microelectron. Nanom. Struct. 27, 2622 (2009). 